\title{
A Proposed Fuzzy Framework for Cholera Diagnosis and Monitoring
}

\author{
Umoh, Uduak $A$. \\ Department of Computer \\ Science, University of Uyo, \\ AKS, Nigeria
}

\author{
Ntekop, Mfon M. \\ Department of Computer \\ Science, University of Uyo, \\ AKS, Nigeria
}

\begin{abstract}
In this paper, a fuzzy expert system for the diagnosis and monitoring of cholera is presented for providing decision support platform to cholera researchers, physicians and other healthcare practitioners in cholera endemic regions. The developed fuzzy expert system composed of four components which include; the Knowledge base, the Fuzzification, the Inference engine and Defuzzification. Object oriented Design tools is adopted in the design of our database. We develop our knowledge based on clinical observations, medical diagnosis and the expert's knowledge. We employ Mamdani's MAXMIN fuzzy inference engine to infer data from the rules developed. This resulted in the establishment of some degrees of influence of input variables on the output. The technique allows for mild, moderate and severe symptoms to be applied in order to get the estimation result. Triangular membership function is employed to evaluate the degree of participation of each input parameter and the defuzzification technique employed is the Centriod of Area (COA).Twenty patients with cholera are selected and studied and the observed results computed in the range of predefined limit by the domain experts. This system will offer potential assistance to medical practitioners and healthcare sector in making prompt decision during the diagnosis of cholera.
\end{abstract}

\section{General Terms}

Artificial Intelligence, Soft computing, Fuzzy Inference System, Object Oriented Design, Expert Systems, Knowledge-Base

\section{Keywords}

Cholera, Fuzzy Logic, object oriented design, healthcare diagnosis and monitoring.

\section{INTRODUCTION}

The act of medical diagnosis and monitoring revolves around structured stored fact which allows for the development of a healthcare system that monitors and diagnoses as well as makes recommendations as regards treatment of ill health condition based on known symptoms. Cholera is an infection in the small intestine caused by bacteria called VibroCholerae and represents major public health problems in the tropics. Health monitoring consists of measures taken to prevent diseases, rather than curing them and diagnosis system is a system which can identify diseases through checking out the symptoms. Due to population variability and difference in cholera presentation, there may be flaws in diagnosis. In recent time, computerization in healthcare allows for various Clinical Support Systems to be constructed; that are programs that can perform as the human expert in narrow problem domain. The relations between diagnoses and their symptoms are hardly ever one-to-one, thus, differentiation of diagnoses that share an overlapping range of symptoms is therefore inherently difficult.Most diagnostic systems are in the form of a rule-based expert system: a set of rules is used to describe certain patterns. Observed data are collected and used to evaluate these rules. If the rules are logically satisfied, the pattern is identified, and a problem associated with that pattern is suggested. Each particular problem might imply a specific treatment. These rules do not take into consideration the uncertainty and the impreciseness of human observed data and reasoning and real world knowledge is characterized by incompleteness, inaccuracy, and inconsistency.

Fuzzy logic is a set of mathematical principles for knowledge representation based on degrees of membership rather than classical binary logic. It is a powerful tool to tackle imprecision and uncertainty and is initially introduced to improved tractability, robustness and low-cost solutions for real world problems [1]. Fuzzy sets have been applied in many fields in which uncertainty plays a key role for which medical diagnosis is an excellent example of vagueness and uncertainty. Fuzzy logic has the ability to make decisions in an environment of imprecision, uncertainty and incompleteness of information. Since fuzzy logic resembles human decision making with its ability to work from approximate reasoning and ultimately find a precise solution, it can be applied in the diagnosis and monitoring of disease including cholera in our society.

Fuzzy framework for diagnosis and health monitoring system for cholera is proposed in this work. Fuzzy logic is a promising technique that can easily capture the required medical knowledge and come up with sound diagnosis decisions as it will estimate the risk in getting cholera based on the risk factors and the symptoms. It increases the number of medical consulting point in hospitals as well as giving some recommendation that suggests the life style that could contribute to the high risk of getting cholera. To achieve our objectives, relevant literatures on fuzzy logic, disease monitoring and diagnosis, database tools, healthcare system and cholera are reviewed and the characteristic of the existing system is studied. Also data are gathered through personal interviews with medical experts/consultants as well as personal observation on 20 cholera patient. Triangular membership function is employed to fuzzify the linguistic variables. Mamdani's Max-Min fuzzy inference engine, [2] and center of gravity defuzzification is employed in the development of our fuzzy inference system. Object oriented design tool (Unified Modeling Language) is adopted for our database design. The implementation of this system is carried out using, Java programming language and My SQL data base

\section{LITERATURE REVIEW}

[3] a develop a fuzzy expert system for the management of malaria (FESMM).This work provides a decision support platform for healthcare practitioners in malaria endemic regions. 35 patients with malaria are selected and computed the results that are in the range of predefined limit by the 
domain experts. Decision support system (DSS) for stress diagnosis and treatment using calibration and fuzzification of cases is an opinion for experts. The proposed solution combines a calibration phase with case-based reasoning approach and fuzzification of cases. The individual cases including calibration and fuzzy membership functions are also used in an autonomous system in home environment for treatment programs for individuals often under high stress [4]. Fuzzy expert system for tuberculosis diagnosis is developed for providing decision support platform to tuberculosis healthcare practitioners in tropical medicine. The fuzzy inference method employed in this paper is the Root Sum Square (RSS) where 30 patients with tuberculosis are selected and computed the results that are in the range of predefined limits by the domain experts

[5] develops a fuzzy logic based patients' monitoring system. He utilizes mobile units that allow for the remote observation and diagnosis of patients in their homes. [6] analyse the possibilities of the integration of different technological and knowledge representation techniques for the development of reinforcement frameworks for the remote control of multiple agents such as wheelchair-type robots. Some technological solutions are discussed regarding the recognition of localization of moving objects by using mobile technologies. [7] review the trend in development of Fuzzy Expert System and application potential over past two and half decades in the medical field, based on the references of 173 articles from 124 journals, several proceedings and web media. [8] design an automatic simple, compact, wireless, personalized and cost efficient pervasive architecture for the evaluation of the stress state of individual subjects suitable for prolonged stress monitoring during normal activity is described. A novel integrated processing approach based on an autoregressive model, artificial neural networks and fuzzy logic modelling allows stress conditions to be automatically identified with a mobile setting analysing features of the electrocardiographic signals and human motion.

[9], develop a remote healthcare monitoring by learning and recognizing human activities of daily living based on fuzzy logic approach. [10], study fuzzy based model for breast cancer diagnosis. [11], present telehealth approach for glaucoma progression monitoring, a Web-Centric, an extension to a previously developed glaucoma expert system that provides access for doctors and patients from any part of the world. [12], addresses the medical diagnosis regarding the normality of a human function in human brain and the diagnosis of haemorrhage and brain tumour. It enhances the control strategies in the medical field to diagnose a disease using fuzzy logic approach. [13] study human activities of daily living recognition using fuzzy logic for elderly home monitoring. The paper we describe a fuzzy logic system for recognizing activities in home environment using a set of sensors: physiological sensors (cardiac frequency, activity or agitation, posture and fall detection sensor), microphones, infrared sensors, debit sensors and state-change sensors. [14], propose an enhanced Neuro-fuzzy model for the proper diagnosis of adult Asthma disease and to foster the proper aid or medication to the patients and make physicians alert for the upcoming disease pattern otherwise they may lack in the process of providing improper medication at right time.

[15], develop a clinically useful diagnostic alarm system for detecting critical events during anaesthesia administration. The performance of the system is validated through a series of off-line tests. [16] presents a Fuzzy model for helping medical diagnosis of Intensive Care Unit (ICU) patients and their vital signs monitored through a multi-parameter heart screen. Intelligent systems techniques are used in the data acquisition and processing (sorting, transforming, among others) it into useful information, conducting pre-diagnosis and providing, when necessary, alert signs to the medical staff. [17], study the application of Fuzzy Cluster Means (FCM or Fuzzy CMean) analysis to the diagnosis of different forms of hepatitis. The paper involves a sequence of methodological and analytical decision steps that enhances the quality and meaning of the clusters produced. The uncertainties often associated with analysis of a hepatitis test data are eliminated by the proposed system. [18], study fuzzy expert system for the management of hypertension. [19], design a decision support system for tuberculosis diagnosis. [20], develop decision support systems using intelligent paradigms for profitability control. [21], study fuzzy rule based framework for effective control of profitability in a paper recycling plant.

\section{RESEARCH OBJECTIVE}

The objective of this paper is to develop a fuzzy framework for healthcare diagnosis and monitoring for cholera. This system will offer potential assistance to medical practitioners and healthcare sector in making prompt decision during the diagnosis of cholera.

\section{RESEARCH METHODOLOGY}

We carefully observe the clinical manifestation of cholera symptoms on patients. Records of past health history on cholera are also collected from the Model Health Clinic, located at no. 33 Udo Ekong Street, Uyo, AKS, Nigeria, being our case study. The data collected includes personal information of patients, clinical records, and diagnosis information. 20 patients are selected, aged between 2 and 41 . Sequel to this, fuzzy techniques is incorporated to develop a fuzzy expert system for the monitoring and diagnosis of cholera.

\subsection{System Architecture}

The architecture of fuzzy logic model for cholera healthcare diagnosis and monitoring is shown in Figure 1. The architecture comprises the knowledge base which, is made of the database model, the fuzzy logic model and the user interface.

\subsubsection{Knowledge base:}

The knowledge base design of the healthcare monitoring and diagnosis system for cholera comprises of database model and a fuzzy logic model. The knowledge base stores both static and dynamic information about the decision variables. It comprises both structured and unstructured knowledge about the problem domain. This knowledge is made up of facts, rules and clinical manifestation of cholera built up by the experts in the field. The facts influence diagnostic monitoring decisions and the rules allow deductions to be made from the information. The structured knowledge is qualitative while unstructured knowledge is acquired by the medical experts through experience.

\subsubsection{Database Model:}

Cholera healthcare diagnosis and monitoring database model is presented in Figure 2. CHCMDS class diagram is shown in Figure 3. Table 1 shows the multiplicity of an association end in CHCMDS class diagram. 


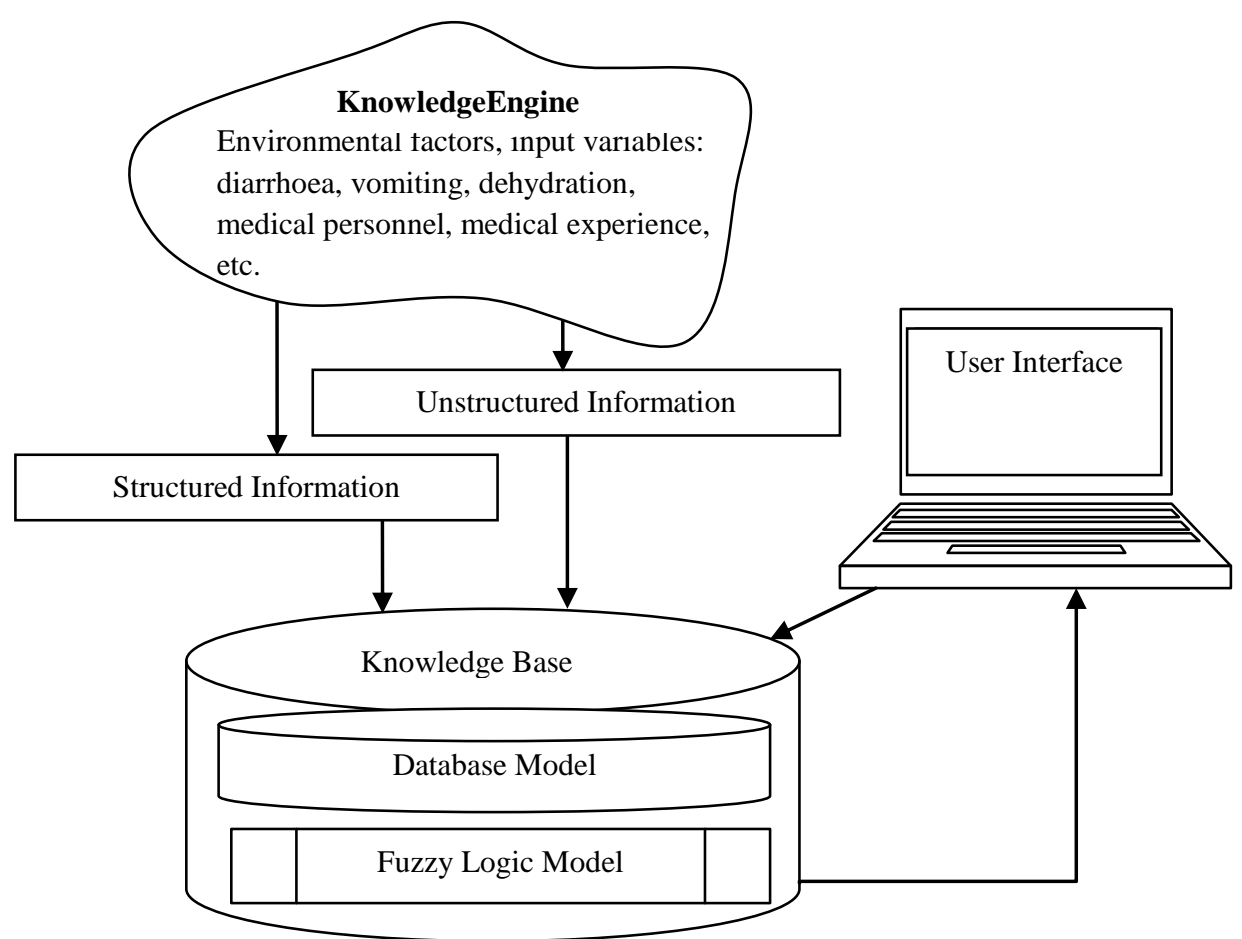

Figure 1: Architecture of Fuzzy logic model for Healthcare Diagnosis and Monitoring

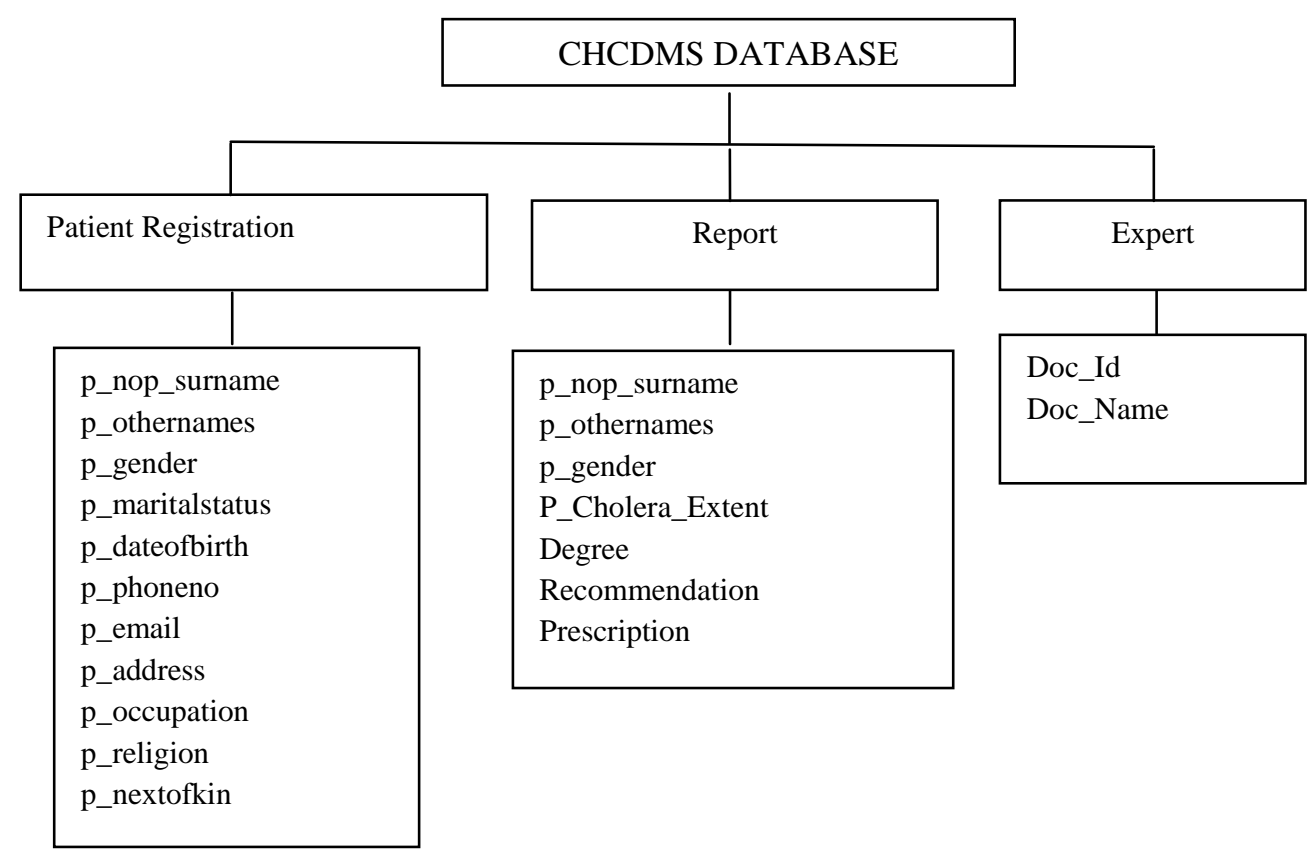

Figure2: Database Model for Cholera Healthcare Diagnosis and Monitoring System. 


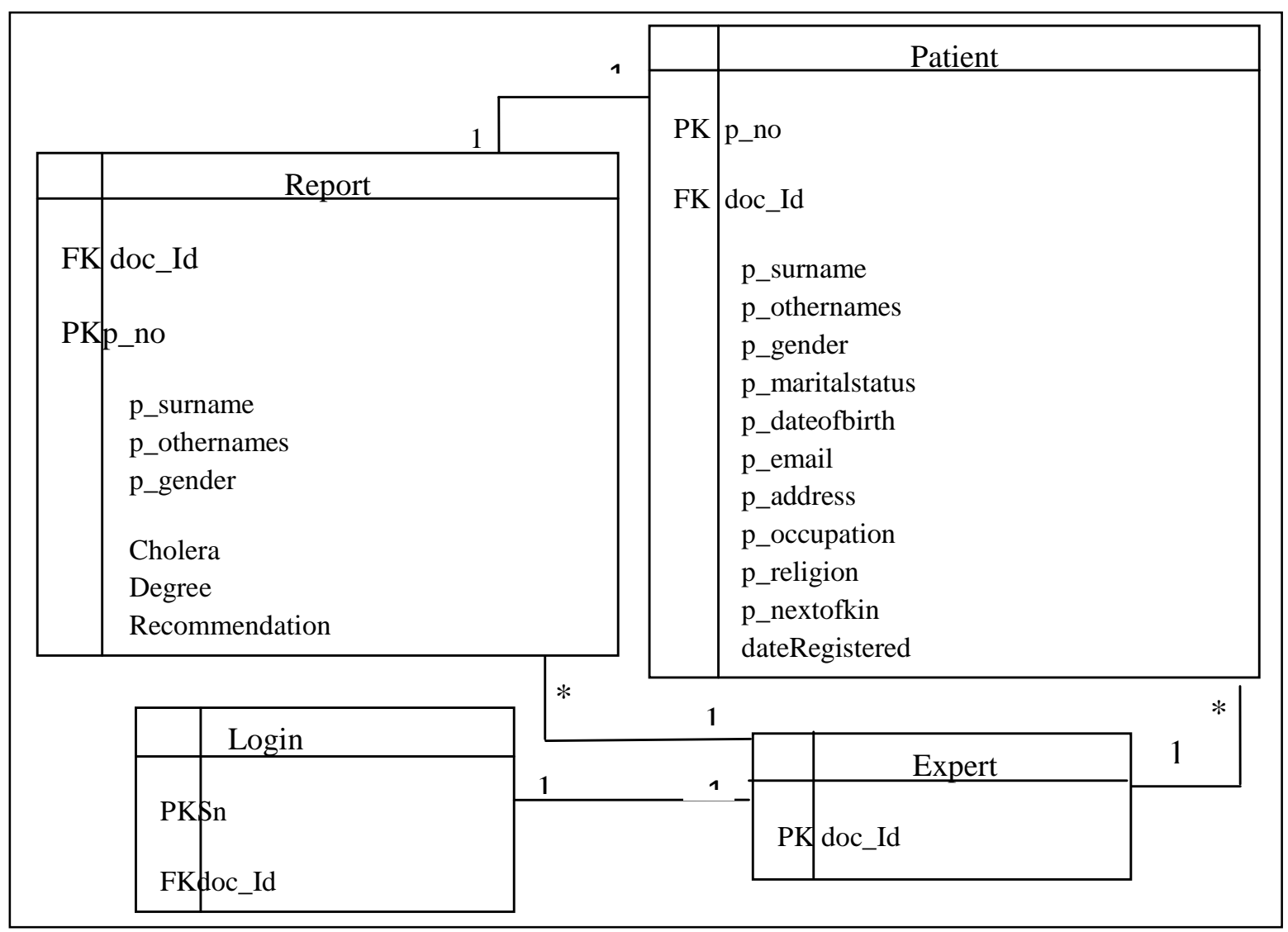

Fig. 3: CHCDMS Class Diagram

Table 1: Multiplicities of Association for the Class Diagram

\begin{tabular}{|c|c|}
\hline Multiplicities & Meaning \\
\hline $0 . .1$ & Zero or one instance. \\
\hline $0 . .^{*}$ or * & $\begin{array}{c}\text { No limit on the number of } \\
\text { instances (including } \\
\text { none) }\end{array}$ \\
\hline 1 & Exactly one instance \\
\hline $1 .{ }^{*}$ & At least one instance \\
\hline$\diamond$ & Aggregation \\
\hline
\end{tabular}

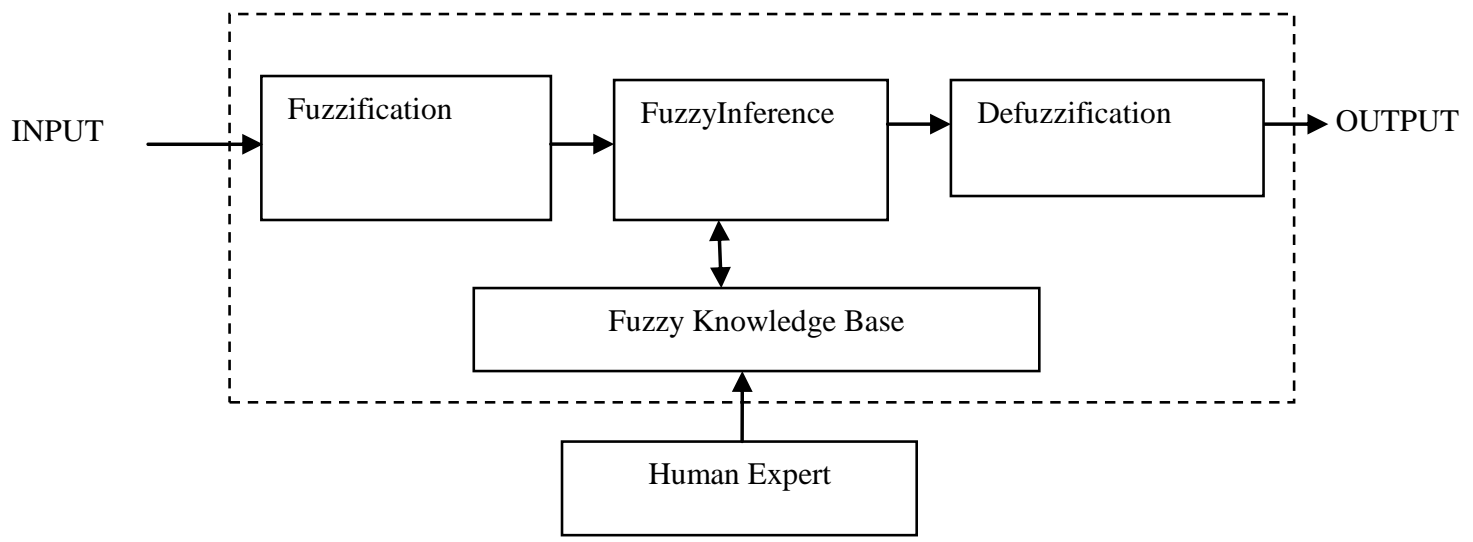

Fig. 4: Fuzzy Logic Model for Healthcare Diagnosis and Monitoring 
CHCMDS class diagram in Figure 3 gives the overview of the system. It shows the different classes and the relationships amongst the system components. This is represented using a single class model. This is because a single class model is static that is, it displays what interacts but not what happens when the different system components interact. Our Class diagram models the CHCMDS information system. The central class is the patients, associated with it are report, login and expert class respectively. The UML class notation is applied with a rectangular box which is divided into three parts; name, attributes, and operation, [22] [23]. Table 1 shows the multiplicity of an association end in the system class diagram, it shows the number of possible instances of the class associated with a single instance of the other end.

\subsubsection{Fuzzy Logic model}

The fuzzy logic model for healthcare diagnosis and monitoring of cholera is shown in Figure 4. This system involves three main processes; fuzzification, inference, and defuzzification.

\subsubsection{Fuzzification}

Fuzzification of data is done by calibrating the input parameters into the horizontal axis and projecting vertically to the upper boundary of membership function to determine the degree of membership. Parameters used in fuzzy logic model are Diarrhoea (DI), Vomiting (VO) and Dehydration (DE). These parameters constitute the fuzzy logic input variables used to generate the fuzzy logic model, and the output parameter is Cholera $(\mathrm{CH})$.

The input parameters are used to map the output value specified in the individual rules to an intermediate output measuring fuzzy sets (mild diarrhoea, moderate diarrhoea, severe diarrhoea, mild vomiting, moderate vomiting, severe vomiting, gradual mild dehydration, moderate dehydration, severe dehydration. 27 rules are developed for this application.

In this paper, the universes of discourse for Diarrhoea (DI), Vomiting (VO), Dehydration (DE) and Cholera (CH) are chosen to be $[0,20],[0,10],[0,15]$ and $[0,10]$ respectively. The sets of linguistic values for the linguistic variables, $D I$, $V O$ and DE are [MI, MO, SE] which represent [mild diarrhoea, moderate diarrhoea, severe diarrhoea] [mild vomiting, moderate vomiting, severe vomiting] [mild dehydration, moderate dehydration, severe dehydration] respectively. The set of linguistic values for Output is [NO, MI, MO, SE] which represent [no cholera, mild cholera, moderate cholera, severe cholera] respectively. The linguistic expressions for $D I, V O, D E$ and output $(\mathrm{CH})$ variables and their membership functions are evaluated using triangular membership function as presented in (2) to (12). Triangular curves depend on three parameters $a 1, a 2$, and $a 3$ and are given by Equation (1); $a 2$ defines the triangular peak location, while $a 1$ and $a 3$ define the triangular end points. During the process, linguistic labels (values) are assigned to $D I, V O$ and $D E$ indicating the associated degree of influence of membership for each linguistic term that applies to that input variable. The output membership function defines the severity level of cholera present on the diagnosed patients.

Degrees of membership (Ux) are assigned to each linguistic value as expressed in (2) to (12) as mild, moderate and severe. The membership function is a graphical representation of the magnitude of participation of each input. It associates a weighting with each of the inputs that are processed, define functional overlap between inputs, and ultimately determines an output response. The rules use the input membership values to determine their influence on the fuzzy output sets of the final output conclusion.

$$
\mu(x)= \begin{cases}0 & \text { if } x<a_{1} \\ x-a_{1} / a_{2}-a_{1} & \text { if } a_{1}<=x<a_{2} \\ a_{3}-x / a_{3}-a_{2} & \text { If } a_{2}<=x<a_{3} \\ 0 & \text { if } x>=a_{3}\end{cases}
$$

The membership functions (MF) and rules defined on the following parameters are as follows:

Diarrh $(x)= \begin{cases}0 & \text { if } x<5 \text { "Mild" } \\ x-5 / 10 & \text { If } 5<=15 \text { "Moderate" } \\ 20-\mathrm{x} / 5 & \text { if } 15<=\mathrm{x}<20 \text { "Severe" } \\ 0 & \text { if } \mathrm{x}>=20 \quad \text { "Very Severe" } \\ 0 & \text { iff } \mathrm{x}<1 \\ \mathrm{x}-1 / 1.5 & \text { if } 1<=\mathrm{x}<2.5 \quad \text { (3) } \\ 6-\mathrm{x} / 2.5 & \text { if } 2.5<=\mathrm{x}<=5 \\ 0 & \text { if } \mathrm{x}>5\end{cases}$

$\mu_{\text {moderate }}(x)= \begin{cases}0 & \text { if } x<5 \\ x-5 / 5 & \text { if } 5<=x<10 \\ 15-x / 5 & \text { if } 10<=x<=15 \\ 0 & \text { if } x>15\end{cases}$

$\mu_{\text {Severe }}(x)= \begin{cases}0 & \text { if } x<15 \\ x-15 / 2 & \text { if } 15<=x<17 \\ 20-x / 3 & \text { if } 17<=x<=20 \\ 0 & \text { if } x>20\end{cases}$

Vomi $(x)= \begin{cases}0 & \text { if } x<3 \quad \text { "Mild" } \\ x-3 / 3 & \text { if } 6<=x<10 \text { "Moderate" } \\ 10-\mathrm{x} / 4 & \text { if } 6<=\mathrm{x}<10 \text { "Severe" } \\ 0 & \text { if } \mathrm{x}>=10 \quad \text { "Very Severe" }\end{cases}$

$\mu_{\text {mild }}(x)=\left\{\begin{array}{cl}0 & \text { if } x<1 \\ x-1 & \text { if } 1<=x<2 \\ 3-x & \text { if } 2<=x<3 \\ 0 & \text { if } x>3\end{array}\right.$ 


$$
\mu_{\text {Moderate }}(x)= \begin{cases}0 & \text { if } x<3 \\ x-3 / 1.5 & \text { if } 3<=x<4.5 \\ 6-x / 1.5 & \text { If } 4.5<=x<6 \\ 0 & \text { If } x>6 \\ 0 & \text { if } x<6 \\ x-6 / 2 & \text { If } 6<=x<8 \\ 10-x / 2 & \text { if } 8<=x<10 \\ 0 & \text { if } x>=10\end{cases}
$$

$$
\mu_{\text {Moderate }}(\mathrm{x})= \begin{cases}\text { Dehydration: } & \text { if } \mathrm{x}<1 \\ \mathrm{x}-1 / 2 & \text { if } 1<=\mathrm{x}<3 \quad \text { If } \mathrm{x}>5 \\ 5-\mathrm{x} / 2 & \text { if } 3<=\mathrm{x}<=5 \\ 0 & \text { if } \mathrm{x}<5 \\ \mu_{\text {Severe }}(\mathrm{x})= & \text { If } 5<=\mathrm{x}<7 \quad \text { (11) } \\ \mathrm{x}-5 / 2 & \text { if } 7<=\mathrm{x}<=10 \\ 0-\mathrm{x} / 3 & \text { If } \mathrm{x}>10 \\ 0 & \text { if } \mathrm{x}<10 \\ \mathrm{x}-10 / 2.5 & \text { if } 10<=\mathrm{x}<12.5 \\ 15-\mathrm{x} / 2.5 & \text { if } 12.5<=\mathrm{x}<15 \\ 0 & \text { If } \mathrm{x}>=15\end{cases}
$$

The linguistic expression for output variables is evaluated and presented in (13) - (16).

$$
\mu_{\text {No Cholera }}(x)= \begin{cases}0 & \text { if } x<0 \\ x / 1.5 & \text { If } 0<=x<1.5 \\ 1.5-x & \text { if } 1.5<=x<2.5 \\ 0 & \text { If } x>=2.5 \\ 0 & \text { if } x<2.5 \\ x-2.5 & \text { if } 2.5<=x<3.5 \\ 3.5-x / 1.5 & \text { if } 3.5<=x<=5 \\ 0 & \text { If } x>5\end{cases}
$$

$\mu_{\text {Moderate }}(x)= \begin{cases}0 & \text { If } x<5 \\ x-5 / & \text { If } 5<=x<6 \\ 7.5-x / 1.5 & \text { If } 6<=x<7.5 \\ 0 & \text { If } x>=7.5\end{cases}$

$$
\mu_{\text {Severe }}(x)= \begin{cases}0 & \text { If } x<7.5 \\ x-7.5 / 0.5 & \text { if } 7.5<=x<8 \\ 10-x / 2 & \text { If } 8<=x<10 \\ 0 & \text { It } x>=10\end{cases}
$$

Fuzzy logic toolbox in Matlab 7.5.0 is employed in this paper for the membership function plots for the diarrhoea, vomiting and dehydration and the outputs (cholera) as shown in Figures 5-9.

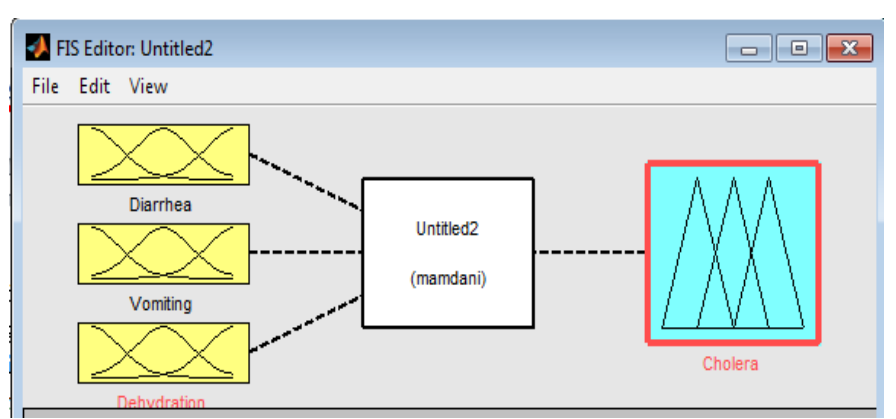

Figure 5: Fuzzy Inference System for Healthcare Diagnosis and Monitoring of Cholera

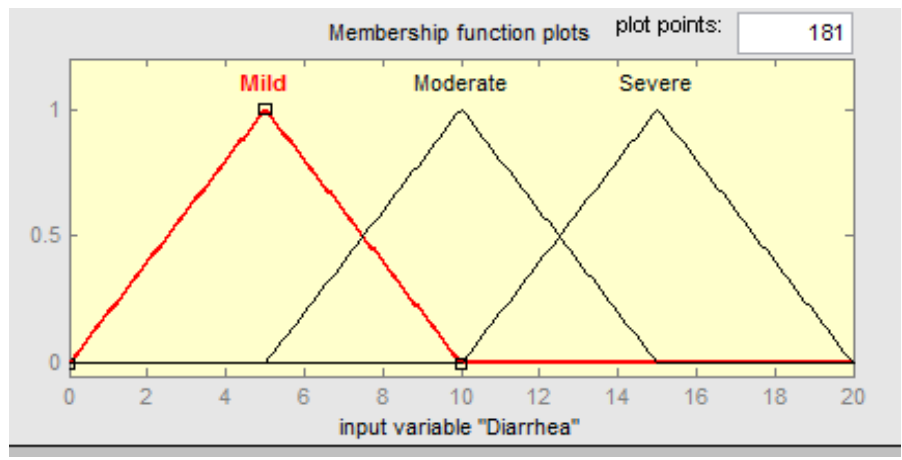

Figure 6: Membership Function Plots for Diarrhoea

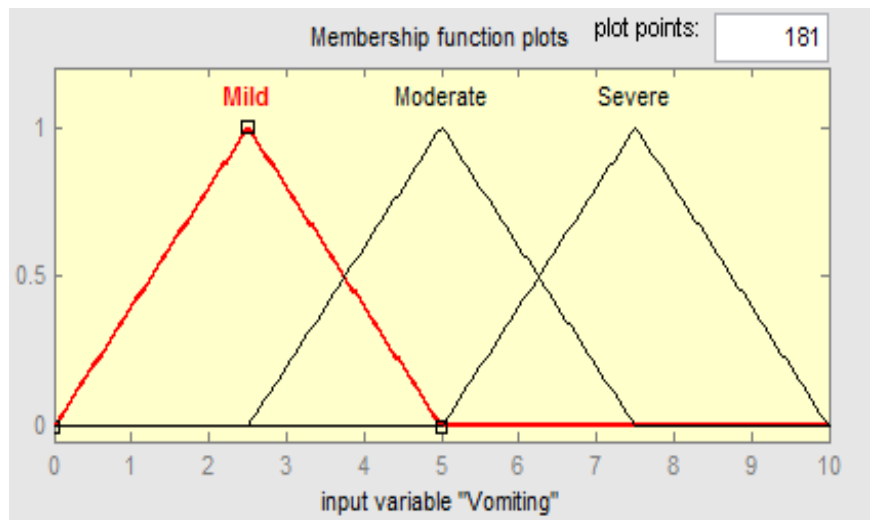

Figure 7: Membership Function Plots for Vomiting 


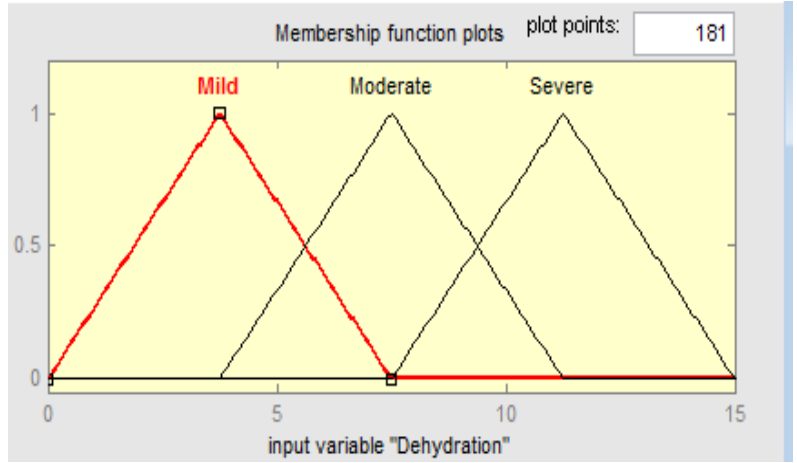

Figure 8: Membership Function Plots for Dehydration

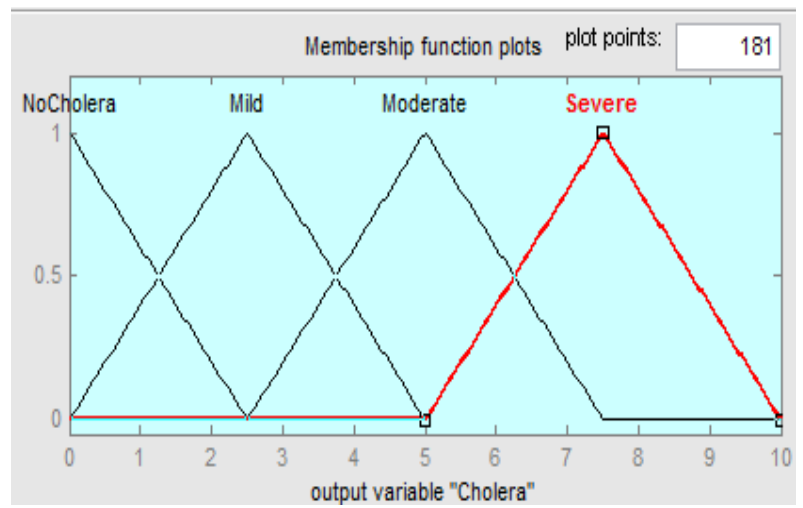

Figure 9: Output Membership Function Plots for Cholera
The degree of membership (DOM) is determined by plugging the selected input parameter (vomiting, diarrhoea or dehydration) into the horizontal axis and projecting vertically to the upper boundary of the membership function(s). For example, when the fuzzy inputs values are; diarrhoea $=10$, vomiting $=7$ and dehydration $=5$, the membership function (fuzzification) result is as corrected to two decimal places, as presented;

Diarrhoea $=10 \Rightarrow$ mild $=0.00 ;$ moderate $=1.0 ;$ severe $=0.0$ Vomiting $=7 \Rightarrow$ mild $=0.00 ;$ moderate $=0.25$; severe $=0.75$ Dehydration $=5=>$ mild $=0.7$ moderate $=0.3$, severe $=0.00$

We obtain our rule base from derivation based on the hospital's records, expert experience, and observation of the clinical features of symptoms in cholera patients between the ages of 2 and 41 . From the above knowledge, 27 rules are defined for the rule base for the decision-making unit and presented in Figure 10.

\footnotetext{
If Diarrhoea is MILD AND Vomiting is MILD AND Dehydration is MILD THEN Cholera is NO CHOLERA If Diarrhoea is MILD AND Vomiting is MILD AND Dehydration is MODERATE THEN Cholera is MILD If Diarrhoea is MILD AND Vomiting is MILD AND Dehydration is SEVERE THEN Cholera is MODERATE If Diarrhoea is MILD AND Vomiting is MODERATE AND Dehydration is MILD THEN Cholera is MILD If Diarrhoea is MILD AND Vomiting is MODERATE AND Dehydration is MODERATE THEN Cholera is MODERATE If Diarrhoea is MILD AND Vomiting is MODERATE AND Dehydration is SEVERE THEN Cholera is MODERATE If Diarrhoea is MILD AND Vomiting is SEVERE AND Dehydration is MILD THEN Cholera is MODERATE If Diarrhoea is MILD AND Vomiting is SEVERE AND Dehydration is MODERATE THEN Cholera is SEVERE If Diarrhoea is MILD AND Vomiting is SEVERE AND Dehydration is SEVERE THEN Cholera is SEVERE If Diarrhoea is MODERATE AND Vomiting is MILD AND Dehydration is MILD THEN Cholera is MILD If Diarrhoea is MODERATE AND Vomiting is MILD AND Dehydration is MODERATE THEN Cholera is MODERATE If Diarrhoea is MODERATE AND Vomiting is MILD AND Dehydration is SEVERE THEN Cholera is SEVERE If Diarrhoea is MODERATE AND Vomiting is MODERATE AND Dehydration is MILD THEN Cholera is MODERATE If Diarrhoea is MODERATE AND Vomiting is MODERATE AND Dehydration is MODERATE THEN Cholera is MODERATE If Diarrhoea is MODERATE AND Vomiting is MODERATE AND Dehydration is SEVERE THEN Cholera is SEVERE If Diarrhoea is MODERATE AND Vomiting is SEVERE AND Dehydration is MILD THEN Cholera is MODERATE If Diarrhoea is MODERATE AND Vomiting is SEVERE AND Dehydration is MODERATE THEN Cholera is SEVERE If Diarrhoea is MODERATE AND Vomiting is SEVERE AND Dehydration is SEVERE THEN Cholera is SEVERE If Diarrhoea is SEVERE AND Vomiting is MILD AND Dehydration is MILD THEN Cholera is MODERATE If Diarrhoea is SEVERE AND Vomiting is MILD AND Dehydration is MODERATE THEN Cholera is MODERATE If Diarrhoea is SEVERE AND Vomiting is MILD AND Dehydration is SEVERE THEN Cholera is SEVERE If Diarrhoea is SEVERE AND Vomiting is MODERATE AND Dehydration is MILD THEN Cholera is MODERATE If Diarrhoea is SEVERE AND Vomiting is MODERATE AND Dehydration is MODERATE THEN Cholera is SEVERE If Diarrhoea is SEVERE AND Vomiting is MODERATE AND Dehydration is SEVERE THEN Cholera is SEVERE If Diarrhoea is SEVERE AND Vomiting is SEVERE AND Dehydration is MILD THEN Cholera is SEVERE If Diarrhoea is SEVERE AND Vomiting is SEVERE AND Dehydration is MODERATE THEN Cholera is SEVERE If Diarrhoea is SEVERE AND Vomiting is SEVERE AND Dehydration is SEVERE THEN Cholera is SEVERE
}

Fig. 11: Fuzzy Rules for Healthcare Diagnosis and Monitoring for Cholera 


\subsubsection{Fuzzy Inference Mechanism}

We adopt Mamdani's MAX-MIN fuzzy inference engine in this paper because experience proved that it gives precise results. In Mamdani's MAX-MIN fuzzy inference method, the rules use the input membership values as weighting factors to determine their influence on the fuzzy output sets of the final output conclusion. We calculate the strength for each of the rule, the firing levels of the 27 rules are computed using the formula in (15), which is a modification based on Umoh et al, 2010 .

$\rho_{\mathrm{i}}=\mathrm{D}_{\mathrm{i}}\left(\mathrm{x}_{0}\right) \wedge \mathrm{V}_{\mathrm{i}}\left(\mathrm{y}_{0}\right) \wedge \operatorname{DHY}_{\mathrm{i}}\left(\mathrm{z}_{0}\right), \mathrm{D}_{\mathrm{i} 2}\left(\mathrm{x}_{0}\right) \wedge \mathrm{V}_{\mathrm{i} 2}\left(\mathrm{y}_{0}\right) \wedge$ $\operatorname{DHY}_{\mathrm{i} 2}\left(\mathrm{z}_{0}\right), \ldots \mathrm{D}_{\text {in }}\left(\mathrm{x}_{0}\right) \wedge \mathrm{V}_{\text {in }}\left(\mathrm{y}_{0}\right) \wedge \mathrm{DHY}_{\text {in }}\left(\mathrm{z}_{0}\right)$

Where, $\rho_{\mathrm{i}}$ is the matching degree of a given input which satisfies the condition of the ith rule and $i=1,2, . ., 27$. The variable $\mathrm{D}$, represent diarrhoea, $\mathrm{V}$ represent vomiting and DHY represent dehydration. In this procedure, the degrees of truths of the rules are determined for each rule by evaluating the nonzero minimum values using AND operator. Then $\rho_{\mathrm{i}}$ is assigned to the rule's consequence $\mathrm{C}_{\mathrm{i}}$ as;

$$
\mathrm{C}_{\mathrm{i}}=\rho_{\mathrm{i}}
$$

The Mamdani's max-min inference engine is evaluated to obtain the individual rule outputs as;

$\mathrm{C}_{\mathrm{i}}^{\prime}=\left(\rho_{\mathrm{i} 1} \wedge \mathrm{C}_{\mathrm{i} 1}\right),\left(\rho_{\mathrm{i} 2} \wedge \mathrm{C}_{\mathrm{i} 2}, \ldots\left(\rho_{\mathrm{in}} \wedge \mathrm{C}_{\mathrm{in}}\right)\right.$

Where, $\mathrm{C}_{\mathrm{i}}{ }^{\prime}$ is the individual rule's consequence.

The overall system output is computed by aggregating the individual rule outputs from all the rules using OR operator as;

$\mathrm{C}(\mathrm{w})=\mathrm{C}_{1}^{\prime} \vee \mathrm{C}_{2}^{\prime} \vee \mathrm{C}_{3}^{\prime} \vee \ldots . \vee \mathrm{C}_{\mathrm{n}}^{\prime}$

\subsubsection{Defuzzification}

The Defuzzification process involves converting a fuzzy set or input into a crisp value. A fuzzy inference system maps an input vector to a crisp output value. In order to obtain a crisp output, we need a defuzzification process. The input to the defuzzification process is a fuzzy set (the aggregated output fuzzy set), and the output of the defuzzification process is a single number.

Although, there are some defuzzification methods, such as, center-of-area (gravity), center-of-sums, max-criterion and mean of maxima, We adopt discrete center of gravity (centroid of area or center of area) approach as shown in (19), for obtaining crisp value for cholera diagnosis. The center of area (gravity) is the most widely used technique because, when it is used, the defuzzified values tend to move smoothly around the output fuzzy region, thus giving a more accurate representation of fuzzy set of any shape. The technique is unique, however, and not easy to implement computationally.

Crisp Output $=\mu(\mathrm{u})=\left(\sum \mu_{\mathrm{A}}(\mathrm{u}) \cdot \mathrm{u}\right) /\left(\sum \mu_{\mathrm{A}}(\mathrm{u})\right)$

Where $\mu_{\mathrm{A}}(\mathrm{u})=$ Membership value in the membership function and $\mathrm{u}=$ Center of membership function.

\section{MODEL EXPERIMENT}

In this paper, we explore Matlab ${ }^{\circledR} /$ Simulink ${ }^{\circledR}$ and its Fuzzy Logic tool box functions to develop a computer simulation showing the user interface and fuzzy inference to assist the experimental decision for the best control action. Results of evaluation of fuzzy rule base inference for three ranges of inputs, Diarrhoea (DI), Vomiting (VO) and Dehydration (DY) are shown in Table 2 and Table 3, respectively.
Table 2: Rule base evaluation for Diarrhoea, Vomiting and Dehydration at 10, 7 and 5

\begin{tabular}{|c|c|c|c|c|c|}
\hline \multirow{2}{*}{$\begin{array}{l}\text { Rule } \\
\text { No. }\end{array}$} & \multicolumn{3}{|c|}{ Input Variables } & \multirow[t]{2}{*}{ Consequence } & \multirow{2}{*}{$\begin{array}{l}\text { Nonzero } \\
\text { Minimum }\end{array}$} \\
\hline & $\begin{array}{l}\text { Diarr- } \\
\text { hoea }\end{array}$ & Vomiting & $\begin{array}{l}\text { Dehy- } \\
\text { dration }\end{array}$ & & \\
\hline 13 & 1.00 & 0.25 & 0.75 & Moderate & 0.25 \\
\hline 14 & 1.00 & 0.25 & 0.30 & Moderate & 0.25 \\
\hline 16 & 1.00 & 0.75 & 0.70 & Moderate & 0.75 \\
\hline 17 & 1.00 & 0.75 & 0.30 & Severe & 0.30 \\
\hline
\end{tabular}

For example, if Rules 13, 14, 16, and 17 fire from the rule base presented in Table 2 when diarrhoea, vomiting and dehydration values are selected at 10,7 and 5 , their corresponding degrees of membership are mild $=0.00$ moderate $=1.00$ severe $=0.00$ for diarrhoea, mild $=0.00$ moderate $=0.25$ severe $=0.75$ for vomiting and mild $=0.70$ severe $=0.00$ moderate $=0.30$ for dehydration. The respective output membership function strengths (range: 0-1) from the possible rules are computed using MAX-MIN inference for cholera (moderate and severe) as;

For Moderate, $\quad \rho_{13}=0.25 ; \mathrm{C}_{13}=0.25$

$$
\begin{aligned}
& C^{\prime}{ }_{13}=(0.25 \wedge 0.25)=0.25 \\
& \rho_{14}=0.25 ; C_{14}=0.25 \\
& C^{\prime}{ }_{14}=(0.25 \wedge 0.25)=0.25 \\
& \rho_{16}=0.75 ; C_{16}=0.75 \\
& C^{\prime}{ }_{16}=(0.75 \wedge 0.75)=0.75
\end{aligned}
$$

For Severe,

$$
\begin{aligned}
& \rho_{17}=0.30 ; C_{17}=0.30 \\
& C^{\prime}{ }_{17}=(0.30 \wedge 0.30)=0.30
\end{aligned}
$$

Overall system output for moderate is computed as;

$$
\begin{aligned}
\mathrm{C}(\mathrm{w}) & =\mathrm{C}^{\prime}{ }_{13} \vee \mathrm{C}^{\prime}{ }_{14} \vee \mathrm{C}^{\prime}{ }_{16} \vee \mathrm{C}^{\prime}{ }_{17} \\
& =0.25 \vee 0.25 \vee 0.75 \vee 0.30 \\
& =0.75
\end{aligned}
$$

Finally, we employ a defuzzification strategy to obtain a deterministic control action.

For inputs $[\mathrm{DI}, \mathrm{VO}, \mathrm{DHY}]=[10,7,5]$ in Table 2, the crisp output is obtained as;

Crisp Output $=((0.25 \times 5)+(0.75 \times 5)+(0.30 \times 7.5)) /(0.25$ $+0.75+0.3)=5.6(56 \%)$ Moderate Cholera

These particular input conditions indicate that the patient has 5.57 (56\% Moderate) degree level of cholera. Therefore moderate cholera is expected with $56 \%$ possibility and required system response. 
Table 3: Rule base evaluation for Diarrhoea, Vomiting and Dehydration at 12.5, 3 and 6

\begin{tabular}{|l|l|l|l|l|l|}
\hline \multirow{2}{*}{$\begin{array}{l}\text { Rule } \\
\text { No. }\end{array}$} & \multicolumn{3}{|c|}{ Input Variables } & \multirow{2}{*}{$\begin{array}{l}\text { Consequenc } \\
\text { e }\end{array}$} & $\begin{array}{l}\text { Nonzero } \\
\text { Minimu } \\
\mathrm{m}\end{array}$ \\
\cline { 2 - 4 } -hoea & Diarr & Vomiting & $\begin{array}{l}\text { Dehy- } \\
\text { dration }\end{array}$ & & \\
\hline 10 & 0.50 & 0.80 & 0.40 & Mild & 0.40 \\
\hline 11 & 0.50 & 0.80 & 0.60 & Moderate & 0.50 \\
\hline 13 & 0.50 & 0.20 & 0.40 & Moderate & 0.20 \\
\hline 14 & 0.50 & 0.20 & 0.60 & Moderate & 0.20 \\
\hline 18 & 0.50 & 0.80 & 0.40 & Moderate & 0.40 \\
\hline 19 & 0.50 & 0.80 & 0.60 & Moderate & 0.50 \\
\hline 21 & 0.50 & 0.20 & 0.40 & Severe & 0.20 \\
\hline 22 & 0.50 & 0.20 & 0.60 & Severe & 0.20 \\
\hline
\end{tabular}

From inputs $[\mathrm{D}, \mathrm{V}, \mathrm{DHY}]=[12.5,3,6]$ in Table 3 , the crisp value is computed as;

Crisp Output $=((0.4 \times 2.5)+(0.5 \times 5)+(0.2 \times 5)+(0.4 \times 5)+$ $(0.2 \times 7.5)) /(0.4+0.5+0.2+0.4+0.2)=4.7 \equiv(47 \%)$ Moderate cholera

The result in (24)indicates that the patient has $4.7(47 \%$ Moderate) degree level of cholera, therefore, moderate cholera is expected with $47 \%$ possibility being required system response. We manipulate the centres of the triangles representing the Mild Moderate and Severe membership functions for the three inputs in order to achieve the desired result.

We insert the values of diarrhoea, vomiting and dehydration presented in Tables 2 and 3 into the rule base under the view rule editor and the computed outputs for all the cases are recorded. We employ Matlab Fuzzy Logic Toolbox to generate the inference mechanism of fuzzy sets in Table 2 and 3 as shown in Figures 12 and 13

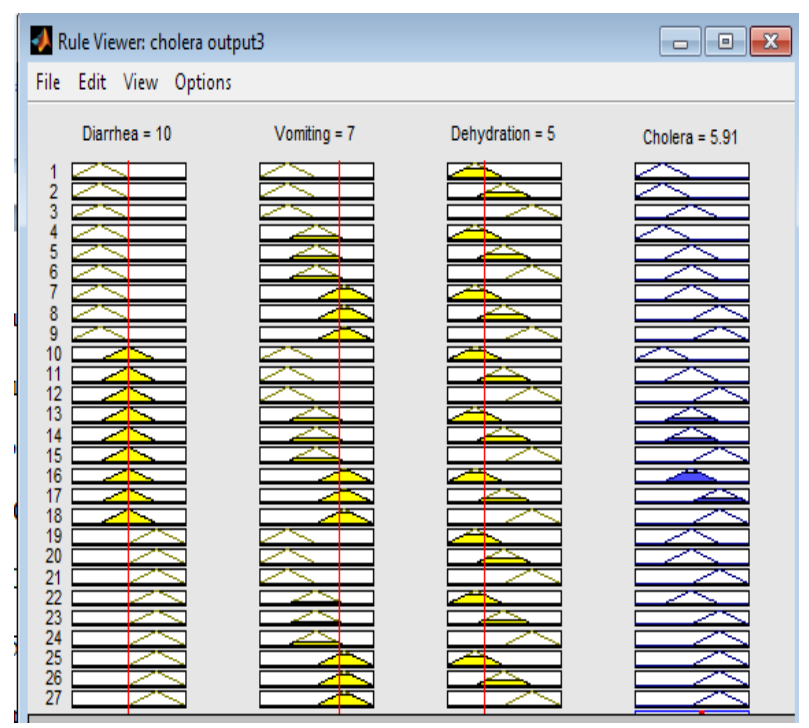

Figure 12: Graphical Construction of the Inference Mechanism of Fuzzy Sets in Table 2.

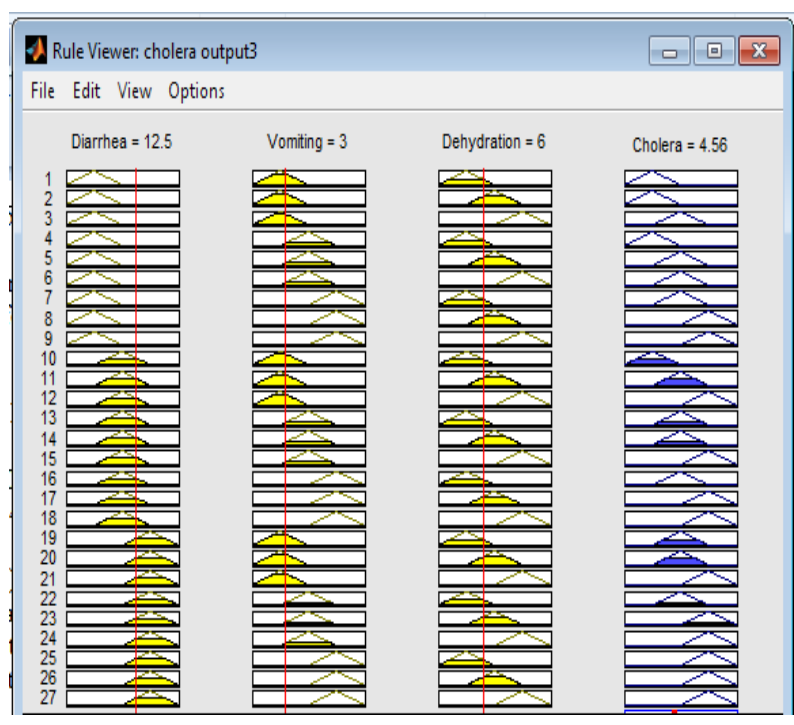

Figure 13: Graphical Construction of the Inference Mechanism of Fuzzy Sets in Table 3.

\section{RESULT AND DISCUSSION}

The healthcare diagnosis and monitoring system is based on fuzzy logic model. It is designed for diagnosis and monitoring of cholera disease in human. This system consists of three input variables: diarrhoea, vomiting and dehydration. The rule base of this system which consists of 27 rules is used to determine the four output parameter values: no cholera, mild cholera, moderate cholera, severe cholera, according to the three input values. Triangular fuzzifier is employed for membership function evaluation; the rule base is designed based on knowledge of domain experts, while Mamdani's inference engine technique is adopted for the work. We explore center of gravity method for the defuzzification of our system. We utilize Fuzzy logic in order to remove uncertainty, ambiguity and vagueness inherent in healthcare diagnosis and monitoring. From the study, apart from assigning linguistics variables such as mild, moderate, severe and to the diagnosis and monitoring, the degree of mildness, moderateness and severity are also evaluated.

Rule evaluation is made for the input values, for example, Diarrhoea $=12.5$, Vomiting=3.0 and Dehydration=6.0. Three linguistics variables values each are given by three input variables. Inference engine uses these values to apply twentyseven inference rules. Matlab Fuzzy Logic toolbox-simulation is used by applying twenty-seven rules. Figures 12 and13 show the simulation results. We evaluate the diagnosis and monitoring of twenty patients using fuzzy logic model and the results show a good performance, being in the range of the pre-defined limits by the domain experts. The essence of the study is to ascertain the degree to which fuzzy logic technique represents the exact diagnosis and monitoring of patients as compared with those of medical doctors. The particular input conditions in (23) indicate that the patient has 5.57 (56\% Moderate) degree level of cholera. Therefore moderate cholera is expected with $56 \%$ possibility and required system response.The result in (24) indicates that the patient has $4.7(47 \%$ moderate) degree level of cholera; therefore, moderate cholera is expected with $47 \%$ possibility being required system response. The outputs no-cholera, mild cholera, moderate cholera and severe cholera show the dependences on inputs, diarrhoea. 


\section{CONCLUSION}

The study has successfully developed a proposed fuzzy framework for cholera diagnosis and monitoring.Both the design model and simulation result are same. The designed system can be extended for any number of inputs. No cholera, mild cholera, moderate cholera and severe cholera all depend on the inputs diarrhoea, vomiting and dehydration. We can define this system for any number of inputs. Similarly, the system can be defined with more than three inputs to achieve more efficient human diagnose and monitoring results. The performance of the proposed system can be improved in future by integrating fuzzy logic with neural network.

\section{REFERENCES}

[1] Zadeh, L. A. (1965). Fuzzy Sets. Information and Control 8: 338-353.

[2] Mamdani, E. H. and Assilian, S. (1975). An Experiment in Linguistic Synthesis with a Fuzzy Logic Controller.International Journal of Man-Machine Studies. 7(1): 113.

[3] Djam, X. Y., Wajiga, G. M., Kimbi, Y. H.and Blamah, N. V. (2011a), A Fuzzy Expert System for the Management of Malaria. Int. J. Pure Appl. Sci. Technol., 5(2) (2011), 84-108,

[4] Begum, S, Ahmed, P. F., Xiong, N. and Schéele, B. (2010). Using Calibration and Fuzzification of Cases for Improved Diagnosis and Treatment of Stress. Department of Computer Science and Electronics, Mälardalen University, SE-72123 Västerås, Sweden.

[5] Al-Dmour, J. A. (2013), Fuzzy Logic based model for patients' monitoring. MSc. Thesis, American University of Sharjah, College of Engineering, Sharjah, United Arab Emirates.

[6] Dzemydiene, D., Bielskis, A. A., Andziulis, A., Drungilas, D., Dzindzalieta, R., Gricius, G. (2010), The Reinforcement Framework of a Decision Support System for the Localization and Monitoring of Intelligent Remote Bio Robots.Proceedings of the 10th International Conference "Reliability and Statistics in Transportation and Communication (RelStat'10), 20-23 October 2010, Riga, Latvia, p. 207-217.

[7] Sikchi, S. S., Sikchi, S and Ali M. S., (2013), Fuzzy Expert Systems (FES) for Medical Diagnosis. International Journal of Computer Applications (0975 8887) 63(11), 7-17.

[8] Tartarisco, G., Baldus, G., Corda, D., Raso, R., Arnao, A., Ferro, M., Gaggioli, A., and Giovanni Pioggia, G. (2012), Personal Health System architecture for stress monitoring and support to clinical decisions. Computer Communications 35, 1296-1305.

[9] Medjahed, H., Istrate, D., Boudy, J., Baldinger, J. L., Bougueroua, L., Dhouib, M. A. and Dorizzi, B. (2012), A Fuzzy Logic Approach for Remote Healthcare Monitoring by Learning and Recognizing Human Activities of Daily Living. Fuzzy Logic - Emerging Technologies and Applications. ISBN 978-953-51-03370; 21-40.
[10] Mishra, M. K., Abirami, T., Soundarya, S. R. and Sulochana, R. R. (2013), A Fuzzy Based Model for Brest Cancer Diagnosis. International Journal of Scientific and Research Publications, 3(3), 1-6.

[11] Ulieru, $M$ and Grabelkovsky, A.(2004), Telehealth Approach for Glaucoma Progression Monitoring. International Journal "Information Theories \& Applications".10, 326-330.

[12] Baig, F. (2011), Design Model of Fuzzy Logic Medical Diagnosis Control. System International Journal on Computer Science and Engineering (IJCSE).3(5), 2093 2109.

[13] Medjahed, H., Istrate, D., Boudy, J and Dorizzi, B. (2009), Human Activities of Daily Living Recognition Using Fuzzy Logic for Elderly Home Monitoring. FuzzyIEEE, 2001-2006.

[14] Patra, S.and Thakur, G (2013), A Proposed Neuro-Fuzzy Model for Adult Asthma Disease Diagnosis. Rupak Bhattacharyya et al. (Eds) : ACER 2013, 191-205.

[15] Mirza, M., GholamHosseini, H. and Harrison, M. J. (2010), A Fuzzy Logic-based System for Anaesthesia Monitoring. 32nd Annual International Conference of the IEEE EMBSBuenos Aires, Argentina, August 31 September 4, 2010, 3974-3974.

[16] Leite, C., Sizilio, G., Neto, A., Valentim, R. and Guerreiro, A. (2011), A fuzzy model for processing and monitoring vital signs in ICU patients. BioMedical Engineering OnLine 2011, 10:68, 1-17.

[17] Imianvan, A. A. and Obi, J. C. (2011), Diagnostic Evaluation Of Hepatitis Utilizing Fuzzy Clustering Means. World Journal of Applied Science and Technology, 3(1), 23-30.

[18] Djam, X. Y. and Kimbi, Y. H. (2011b).Fuzzy Expert System for the Management of Hypertension. Pacific Journal of Science and Technology. 12(1): 390-402.

[19] Djam, X. Y and Kimbi, Y. H. (2011c).A Decision Support System for Tuberculosis Diagnosis. Pacific Journal of Science and Technology. 12(2):410-425.

[20] Umoh E. A, Nwachukwu, E. O, Umoh A. A and Eyoh, I. J. (2012). Decision Support Systems Using Intelligent Paradigms for Profitability Control. Journal of Emerging Trends in Engineering and Applied Sciences (JETEAS) 3 (4): 622-626 (C) Scholarlink Research Institute Journals, (ISSN: 2141-7016).

[21] Umoh U.A, Nwachukwu, E. O and Obot, O. U. (2010). Fuzzy Rule based Framework for Effective Control of Profitability in a Paper Recycling Plant. Global Journal of Computer Science and Technology, (10)10: 56-67

[22] Siau, K and Cao, Q., 2001. "Unified Modeling Language (UML): A Complexity Analysis." Journal of Database Management. 12(1):26-34.

[23] Urban, S.D. and Dietrich, S. W., 2003. "Using UML Class Diagrams for a Comparative Analysis of Relational, Object-Oriented, and Object-Relational Database Mappings." ACM SIGCSE Bulletin. 35(1):2125. 